\title{
Analysis of Simplifications Applied in Vibration Damping Modelling for a Passive Car Shock Absorber
}

\author{
Lukasz Konieczny \\ Faculty of Transport, Silesian University of Technology, Krasińskiego 8, 40-019 Katowice, Poland \\ Correspondence should be addressed to Łukasz Konieczny; lukasz.konieczny@polsl.pl
}

Received 22 October 2015; Revised 24 January 2016; Accepted 27 January 2016

Academic Editor: Minvydas Ragulskis

Copyright ( 2016 Łukasz Konieczny. This is an open access article distributed under the Creative Commons Attribution License, which permits unrestricted use, distribution, and reproduction in any medium, provided the original work is properly cited.

\begin{abstract}
The paper presents results of research on hydraulic automotive shock absorbers. The considerations provided in the paper indicate certain flaws and simplifications resulting from the fact that damping characteristics are assumed as the function of input velocity only, which is the case of simulation studies. An important aspect taken into account when determining parameters of damping performed by car shock absorbers at a testing station is the permissible range of characteristics of a shock absorber of the same type. The aim of this study was to determine the damping characteristics entailing the stroke value. The stroke and rotary velocities were selected in a manner enabling that, for different combinations, the same maximum linear velocity can be obtained. Thus the influence of excitation parameters, such as the stroke value, on force versus displacement and force versus velocity diagrams was determined. The 3D characteristics presented as the damping surface in the stoke and the linear velocity function were determined. An analysis of the results addressed in the paper highlights the impact of such factors on the profile of closed loop graphs of damping forces and point-type damping characteristics.
\end{abstract}

\section{Introduction}

A shock absorber is one of the most important elements in a vehicle suspension system. The role of shock absorbers is to provide better handling, comfort, and safety while driving a car by controlling the damping of the relative movement between the wheel and the car body. An ideal shock absorber should guarantee constant contact with the road pavement. It must also be designed in a manner ensuring durability. And for purposes of comfort, the emission of noise and vibrations should be limited [1-5].

Laboratory experiments are more repeatable than onroad driving sessions, whereas laboratory tests enable cost reduction and may be performed more rapidly [6-9]. The shock absorber is one of the most nonlinear and complex elements to model. In fact, the absorber damping force is a strongly nonlinear function of piston velocity, being asymmetric against the velocity sign (compression and rebound). Moreover, different values of damping force can be obtained with the same value of piston velocity showing unsymmetrical hysteretic phenomenon in an experiment conducted at an
MTS testing machine. The current method for characterising dynamic properties of shock absorbers in models involves testing at discrete frequencies, displacements, and preloads using a testing machine. Vibration tests performed using a servohydraulic tester are intended to quantify and rank the intensity of vibrations generated by shock absorbers [10].

Determination of shock absorber characteristics at a special testing station is an important preliminary stage for further simulation studies of vehicle dynamics. It is usually carried out by providing a force-velocity or a characteristic diagram where the force data obtained from the test are simply plotted against the corresponding velocity values. These diagrams show hysteresis loops, that is, a finite area enclosed within curves. This is a consequence of the force being dependent on the position. A reduced form of the characteristic diagram is usually produced by testing the absorber several times, each time at the same frequency, but with a different amplitude. The maximum and minimum force and velocity values are each time determined and subsequently plotted. This procedure actually generates an envelope of the true characteristic diagram and much information is discarded 
as a consequence of the foregoing. Similar graphs of force against displacement (working diagrams) can also be plotted, providing information about the absorber's dependence on the position. However, a solution alternative to the above is to plot the force as a function of displacement and the velocity as a restoring force surface above the displacement-velocity plane [11].

\section{Fundamentals of the Damping System Modelling}

In the engineering practice of modelling of the damping function performed by a car shock absorber, the simplest damping model one often adopts is the Voigt hypothesis of viscous damping assuming that there is a proportionality relation between damping forces and speed (being a derivative of displacement) [13-17].

A schematic representation of a model of viscous damping and linear damping characteristic has been provided in Figure 1.

According to this viscous damping model, the characteristic of resistance forces is a linear function of speed described by the following dependence:

$$
F(x, \dot{x})=c \dot{x},
$$

where $c$ is linear factor of viscous resistance damping.

In this case, damping factor $\zeta$ is described by the following dependence:

$$
\zeta=\frac{c}{2 m \omega}
$$

where $m$ is mass and $\omega$ is periodicity of undamped free vibrations.

With regard to problems related to typical studies of dynamics of vertical vibrations occurring in car suspension systems, such an assumption is usually made. For the sake of basic and general studies, one often applies a simplified twomass model of an automotive vehicle referred to as a quartervehicle model. This model is based on an assumption that one can disconjugate a system of equations describing the car motion into two subsystems representing the car's front and rear sections. The foregoing assumption may be fulfilled when the coefficient of mass distribution equals one, this being a relatively frequent case in automotive vehicles which allows for the disconjugation of coordinates for the front and the rear vehicle section (no inertial coupling occurs). In numerous instances of vertical motion analysis for an automotive vehicle, such a model suffices for basic analyses of the impact exerted by selected parameters or for analysis of systems used to control suspension parameters, and so forth [18-21].

In the model in question, both sprung $\left(m_{1}\right)$ and unsprung masses $\left(m_{2}\right)$ are separated by the elastic element (helical spring $k 1$ ) and the damping element (shock absorber $c 1$ ), whereas between the unsprung mass and the kinematic input from the road profile, there is the elastic-damping element (pneumatic tyre $k 2$ and $c 2$ ). A two-mass quarter-vehicle model of an automotive vehicle has been provided in Figure 2.

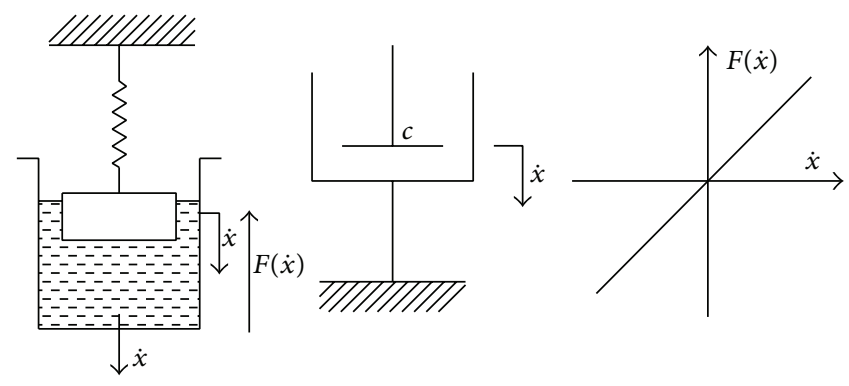

FIGURE 1: Viscous shock absorber model.

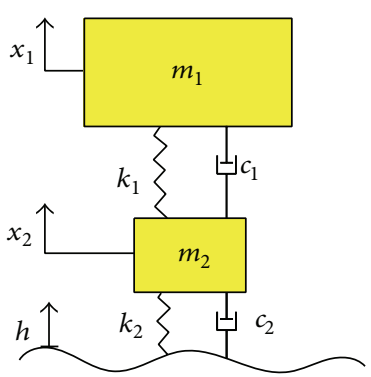

FIGURE 2: Quarter-vehicle automotive suspension model.

For the physical model depicted in Figure 2, based on second-order Lagrangian equations, the following simple motion equations are derived:

$$
\begin{aligned}
& m_{1} \ddot{x}_{1}+c_{1}\left(\dot{x}_{1}-\dot{x}_{2}\right)+k_{1}\left(x_{1}-x_{2}\right)=0, \\
& m_{2} \ddot{x}_{2}+c_{1}\left(\dot{x}_{2}-\dot{x}_{1}\right)+c_{2}\left(\dot{x}_{2}-\dot{h}\right)+k_{1}\left(x_{2}-x_{1}\right) \\
& \quad+k_{2}\left(x_{2}-h\right)=0 .
\end{aligned}
$$

Results of numerous studies imply that, by assuming a linear model, one introduces too far-reaching simplifications. In many cases, problems of nonlinear nature of damping cannot be disregarded. Insofar as for relatively low speeds assumed in modelling of a hydraulic car shock absorber, the linear model may prove sufficient, in practice, the shock absorber design determines its asymmetric nonlinear characteristic [24-26].

There are certain problems connected with implementation of the shock absorber model in a full-vehicle simulation program for rough road examinations if the model is validated in laboratory experiments using the shock absorber testing device only. While driving on a rough road, the shock absorber is used over its entire length of stroke, and occasionally buffers are reached. The stroke of a standard shock absorber testing machine is considerably shorter than that of the shock absorber, and even in cases when the length of stroke of the testing machine can be increased, it must be at least a few millimeters smaller than that of the shock absorber in order to avoid possible damage to the testing machine. Thus, the region that is bounded by the trajectory for the maximum harmonic excitation frequency does not extend to the entire length of the shock absorber stroke. That 
finding confirms the validity of the research characteristics in a wide range of strokes. It should be noted that the presented research results provide important information for the experimental validation of complex models where shock absorber fluid flows and pressure changes are analysed.

\section{Testing at an Indicator-Type Station}

Shock absorber tests are conducted at testing stations enabling measurements of motion parameters (acceleration, input speed) and the shock absorber force (shock absorber resistance) on kinematic input function. For a test stand with electromechanical drives, it is usual to adjust the frequency by means of either a variable speed DC motor or a variable ratio gearbox. Variation of stroke may be possible to obtain by dismantling the apparatus so that the stroke is set to provide the desired maximum speed within the limits of the damper and the test apparatus. With electrically driven test devices, there will usually be some variation of the crank angular velocity, since it is impractical to use a very large flywheel. Because of certain limitations, electromechanical testers are usually limited to small low-power units. They are suitable for limited testing and comparative low-speed work, such as matching at low speeds. For larger testers, it is usually preferred that a hydraulic drive is used (Figure 3) [27-30].

Such testing stations are often used for durability tests of shock absorber. One may also conduct tests in a climate chamber simulating external weather conditions (e.g., humidity, temperature, and salinity) or, as in studies of McPherson suspension shock absorbers, durability tests assuming the impact of a lateral force.

Studies of telescopic shock absorbers conducted at indicator-type testing stations make it possible to plot operation graphs which illustrate damping forces in the function of displacement and linear velocity of the shock absorber piston rod against its housing (Figure 4).

Shock absorber damping constant $c$ equals the proportion between the force determined by the point of intersection of the operation graph and the $x_{1}$-axis (point 4 in Figure 4) and a product of pulsatance of input function $\omega$ and arm length $R:$

$$
c=\frac{c R \omega}{R \omega}=\frac{F_{4}}{R \omega}=\operatorname{tg} \beta .
$$

The value of conventional elasticity constant $k_{u}$ equals the tangent of the inclination angle of the line crossing the beginning of the coordinate system and the point of tangency with lines parallel to the $x_{1}$-axis (point 3 in Figure 4) for extreme values of the input stroke:

$$
k_{u}=\frac{F_{3}}{R}=\operatorname{tg} \alpha .
$$

It should be noted that $k$ and $c$ are treated as constants (independent of displacement amplitude and frequency) in the time domain, while the complex dynamic stiffness is a function of frequency if the excitation is assumed as a simple harmonic. In many simulation studies, with regard to damping characteristics, the course of force in the function

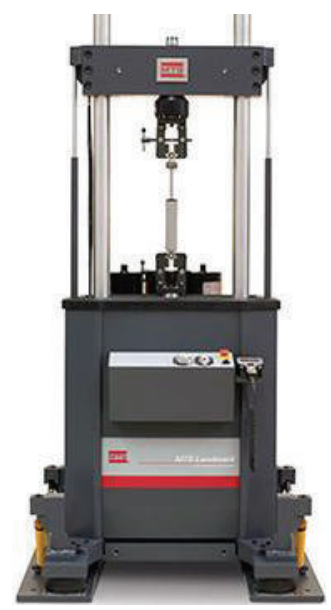

FIGURE 3: Shock absorber testing station [12].

of velocity is approximated with polynomial functions of velocity, different for the compression and the rebound process. The choice of coefficients for these polynomials is based on experience from a test stand.

By studying shock absorbers installed in contemporary cars of nonsymmetrical characteristics of damping adjusted with overflow valves, one obtains graphs of operation different from elliptic (Figure 5). A typical damper is designed to exert only about half the force in bump as in rebound. A large rebound coefficient helps one stop the wheel from dropping into potholes. However, it is now claimed that the best allround behaviour is achieved if, for the given total damping, $60-70 \%$ accounts for the rebound stroke. The shock absorber resistance force opposes displacements of the vibrating mass proportionally to the oscillating motion velocity, and it can be described by the following dependence:

$$
F_{a}=c\left(\frac{d x}{d t}\right)^{i}=F v^{i},
$$

where $c$ is shock absorber damping constant, $v=d x / d t$ is velocity of the car body vibrations against wheels, and $i$ is exponent characterising the course of dependence between damping force and velocity.

The shock absorber is a typical nonlinear system and its damping force modelling has become the research highlight. The nonlinear modelling methods comprise a parametric model and a nonparametric one. The parametric model accounts for the internal fluid flow in shock absorbers and the real throttle structure, while the nonparametric model is mainly based on actual measurement while its inner structure is ignored. Therefore, in order to obtain the damping coefficient of the shock absorber and its motion regularity correctly, it is necessary to establish the damping characteristics at a testing station.

In order to study shock absorbers, one uses devices referred to as indicator-type testing stations which enable measurements of values of forces, displacements, and velocity on variable input parameters (values of angular velocity 


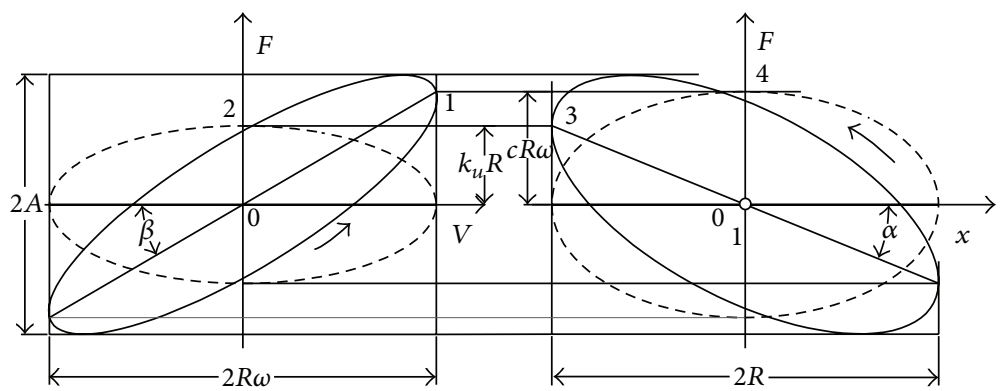

FIGURE 4: Theoretical graph of the ideal shock absorber operation [4].
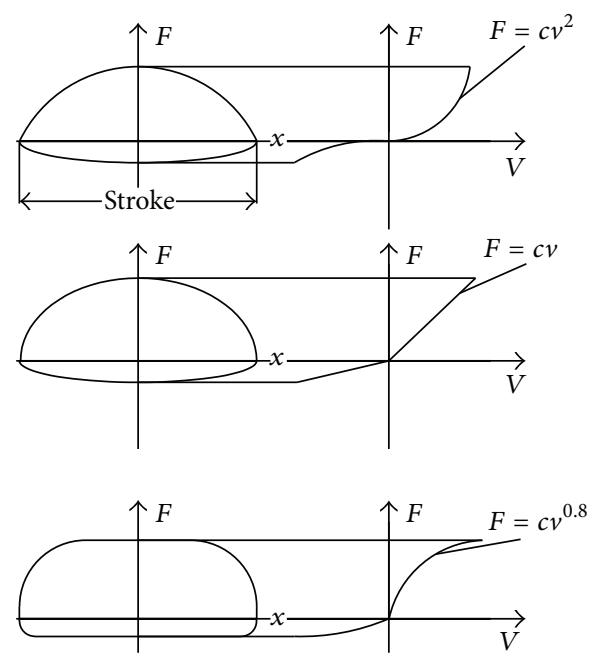

FIGURE 5: Sample car shock absorber operation graphs and the corresponding characteristics of damping (progressive, digressive, and linear).

and/or piston rod stroke). One of such testing stations can be found in the Laboratory of Automotive Vehicle Dynamics at the Faculty of Transport of the Silesian University of Technology, and it has been depicted in Figure 6 .

The measurement system of the aforementioned testing station features a CL 16 type bidirectional strain gauge with the operating range of $\pm 2.5 \mathrm{kN}$ used for direct force measurement. The gauge's measurement uncertainty is $0.5 \%$ of the value measured between 10 and $100 \%$ of the measuring range. A PTx 200 series transformer-type linear displacement transducer together with the MPL 104 displacement gauge was used to measure displacements. The measurement uncertainty of this transducer is $0.5 \%$ of the measurement range. Signals received from transducers were recorded using the SigLab 20-220A two-channel analyser and stored on a computer hard drive in a format compatible with the Matlab software. The measurement uncertainty of the SigLab 20-22 recording device is $\pm 0.0025 \%$ of the measurement range. The overall uncertainty of the measurement chain is less than $1 \%$.

The testing procedure followed at the aforementioned testing station comprised several steps:

(i) Prior to the shock absorber testing, a short (ca. one minute) operating cycle was conducted in order to warm up the shock absorbing liquid.

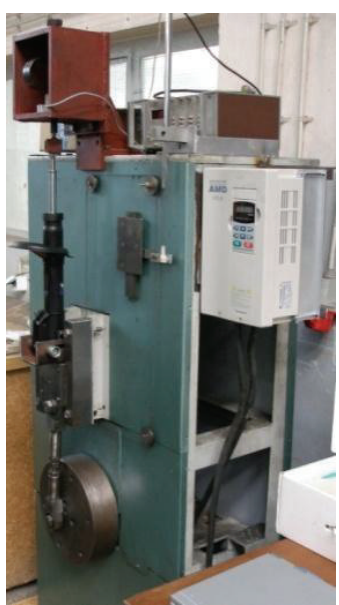

FIGURE 6: Indicator-type testing station for studying shock absorber characteristics.

(ii) The next step comprised recording of force displacement signals at the sampling rate of $2048 \mathrm{~Hz}$. Depending on the input velocity, the recording time ranged from 15 to more than 60 seconds, each time 
ensuring that at least 25 full operation cycles were recorded, comprising the motion of rebound and compression [31].

According to the principles envisaged for plotting graphs of shock absorber operation and characteristics, an averaged loop based on the courses recorded was assumed as representative. For an averaged graph, points of damping characteristics were established (corresponding to values of forces for maximum linear velocity of the piston rod motion for both compression and expansion of the shock absorber). The measurement uncertainty for the these values did not exceed 5\%. The points thus established for successive input function parameters enable determination of the damping characteristic in the form of a curve (Figure 7).

The hysteresis phenomena which become obvious in the phase plot showing the force versus the velocity curve at higher frequencies are one important reason why a simple damper model may not adequately predict certain dynamic behaviour. Hysteresis is the separation of compression and expansion lines in the force-velocity graph. The rebound part of the stroke manifests itself as the positive force and the compression part as the negative force in the diagram. The main causes for hysteresis are gas compression, oil compressibility, oil inertia, rubber mounting pieces, friction, the pressure required to open check valves, the delay until the check valves close, and the fluid cavitation. The shock absorber oil is in contact with gas in the reserve chamber. As a matter of fact, a small fraction of the gas will become mixed with the oil. The consequence is a reduction of the bulk modulus of the mixture (gas and oil). Oil compressibility causes elastic energy to be stored in the absorber. Cavitation is the damper fluid vaporization caused by the fluid pressure dropping below its vapor pressure.

\section{Results of Tests Conducted at the Indicator-Type Station}

What proves to be a particularly important aspect when determining parameters of damping performed by car shock absorbers at a measuring station is the permissible spread of the course of characteristics for the given shock absorber type. Each manufacturer defines strict tolerance ranges which must contain characteristics of a finished product. It is one of the most important reasons for small differences, mainly of quantitative nature, which may occur in the given type of shock absorbers (Figure 8).

Through a comparative analysis of the graphs developed, one may assess that there are practically no qualitative differences between individual shock absorbers. One may find quantitative differences reaching several percent for values attained at the maximum input velocity (Figure 9).

These differences cause small discrepancies in the damping characteristics established with reference to individual points (Figure 10).

For the sake of a more reliable comparison, it has been proposed (by integrating the velocity graph, Figure 10) that the shock absorber damping power should be determined as the area under the velocity characteristic (Figure 11).

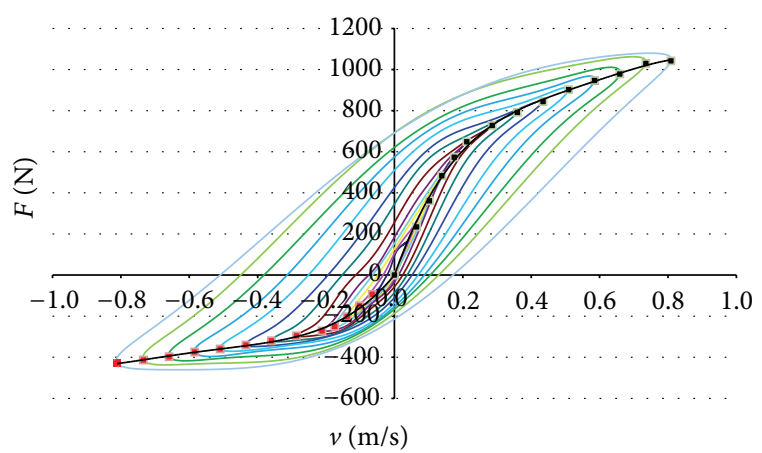

FIGURE 7: Velocity graphs (for different input function frequencies) and characteristics of damping (black line).

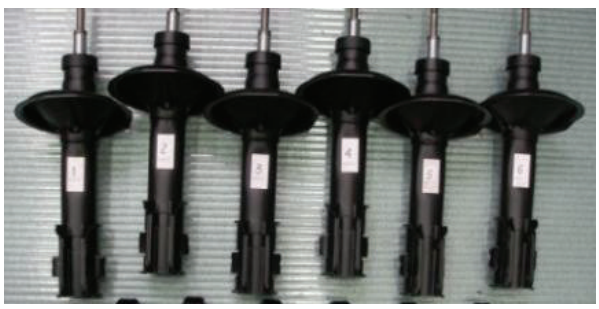

FIGURE 8: Test sample shock absorbers of the same type.

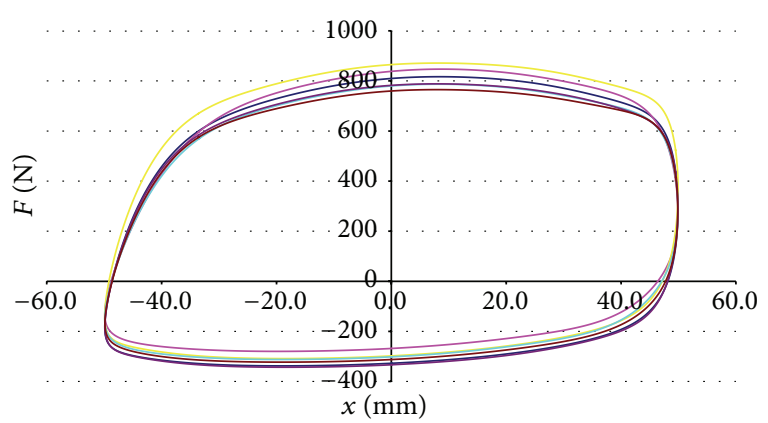

FIGURE 9: Shock absorber operation graphs for the chosen input function frequency.

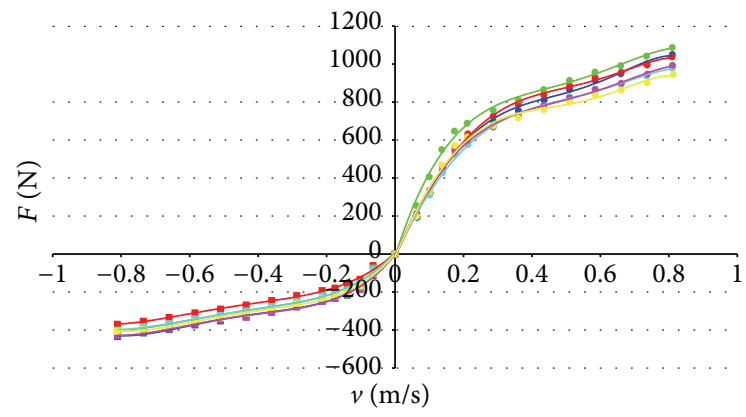

FIGURE 10: Characteristics obtained for shock absorbers of the same type. 


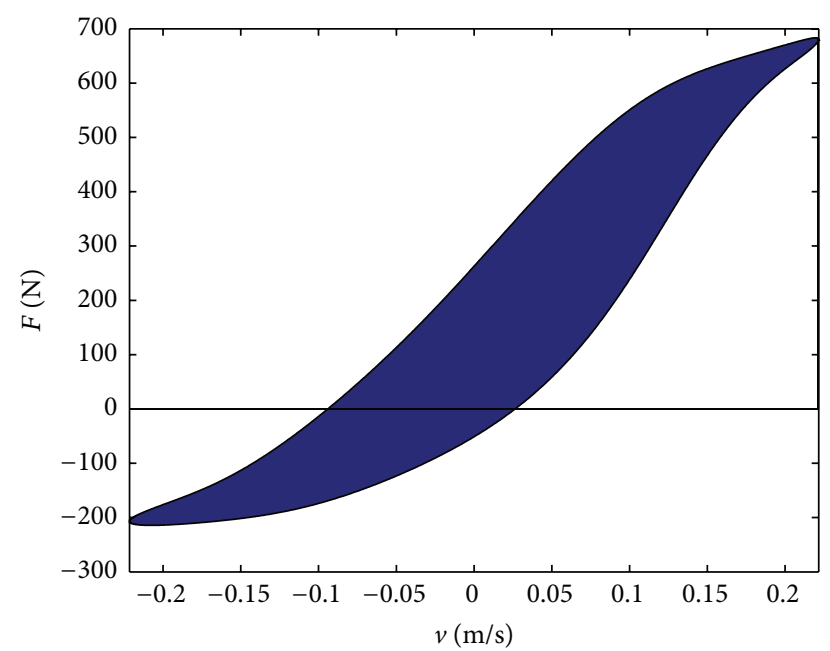

FIGURE 11: Velocity characteristic along with the area calculated (damping power).

The energy dispersed in the course of a single cycle may be expressed with the following formula:

$$
E_{\text {cycle }}=\oint F d x=\oint F v d t
$$

hence the damping power in a single cycle

$$
P_{\text {cycle }}=\oint F d v
$$

Figure 12 shows the damping power values calculated assuming the input stroke of $100 \mathrm{~mm}$ and variable values of the input function frequency set on the waveguide.

Having compared the damping power values calculated for average velocity graphs, one may find that differences between individual shock absorbers practically never exceed several percent. The foregoing confirms the high quality and repeatability of parameters of individual shock absorbers.

\section{Effect of Input Function Parameters on Damping Characteristics}

In simulation studies of dynamics of suspension systems, a car shock absorber is assumed to be an element of viscous damping, whereas the force of resistance to motion depends on linear velocity only. For low frequency input functions, one does not take the phenomenon of apparent shock absorber rigidity into account, and the effect of the stroke amplitude on damping characteristics is also disregarded.

In real conditions of the shock absorber operation in the suspension system, axle vibration frequencies are higher than vibration frequencies of the car body and their amplitudes are low. Bearing the frequent change of the piston rod motion

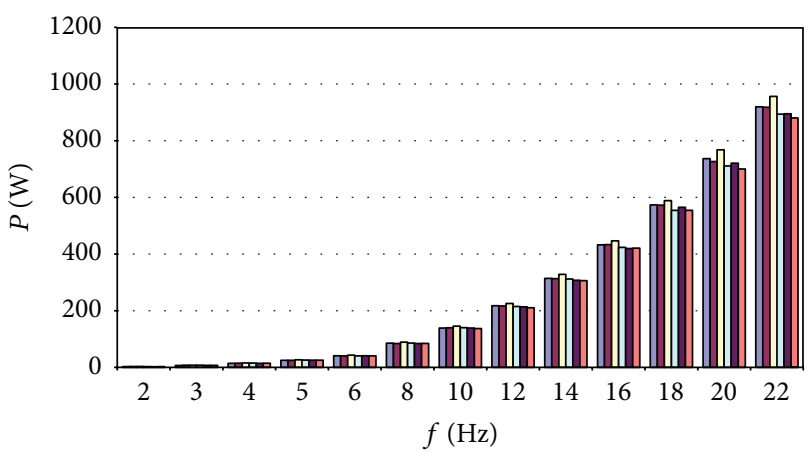

FIGURE 12: Damping power graphs for individual shock absorbers of the same type.

direction in mind, under such conditions, small amounts of shock absorbing liquid flow through valves. This triggers changes in the courses of damping forces for high frequencies on low amplitudes. A specific maximum value of input velocity may be obtained in two ways, that is, by changing the operating stroke length on constant input function frequency (Figure 13) or, on constant stroke length, by changing the input function frequency (Figure 14) [26, 32-35].

There is a hypothesis conveyed in the literature of the subject that, regardless of the method envisaged for obtaining the given maximum linear input velocity, the shock absorber's response will always be identical. The foregoing is a correct assumption provided that the condition of low input function frequencies is satisfied. Under real conditions of vehicle motion, vibrations of a broad frequency range occur, whereas the piston rod motion velocities may reach several meters per second on different stroke values. Profiles of characteristics and graphs of operation established at testing stations depart from theoretical elliptic graphs. The said discrepancies are due to cavitation, inertia of valves, liquid quality, friction between moving elements, and various other factors. Also the characteristics and the damping forces established are dependent on the shock absorber stroke to a certain extent. Sample results of similar analyses illustrating the area of damping forces, in the function of input velocity and stroke, have been provided in Figure 15 [22, 36-38].

Further illustrations, that is, Figures 16 and 17, show sets of damping characteristics in the form of point-type values of forces occurring for the given stroke on maximum linear velocities.

An analysis of the point-type damping characteristics obtained for the motion of rebound and compression implies that, for small stroke values, damping forces decline on higher velocities. This phenomenon has been confirmed for both the compression and the rebound motion.

The point-type characteristics depicted on a plane have been expanded towards the other input function parameter, namely, the stroke, and thus the area of damping forces has been obtained in the function of velocity and stroke value (Figure 18). 


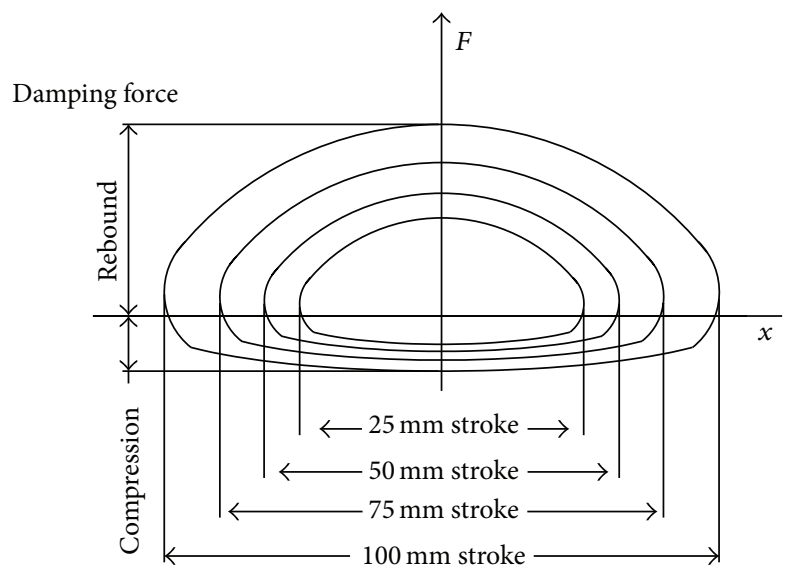

FIGURE 13: Determination of damping characteristics for constant value of angular input velocity and variable stroke value [22].

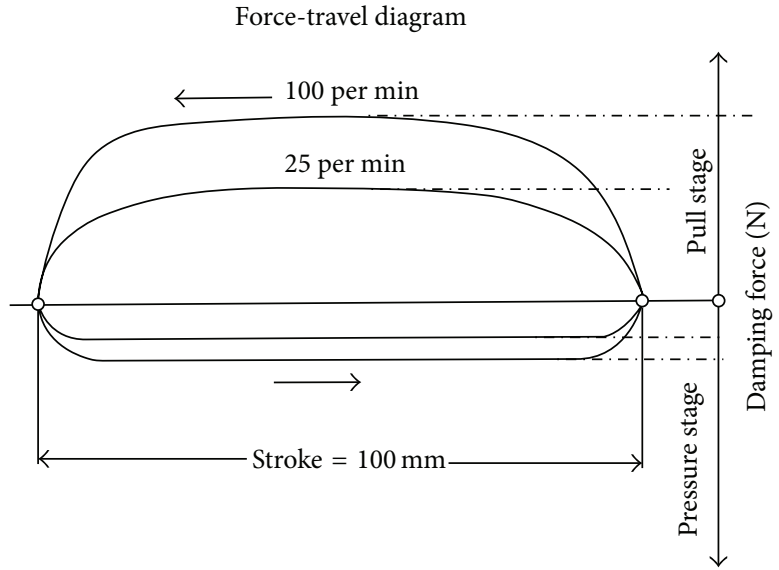

Force-velocity curve

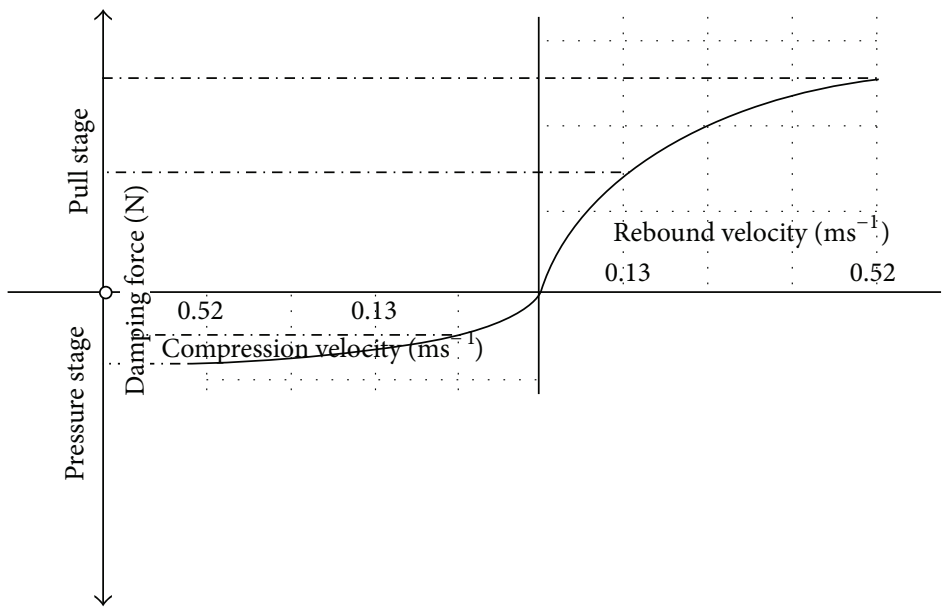

FIGURE 14: Determination of damping characteristics for variable values of angular input velocity and constant stroke value [22].

\section{Conclusions}

The considerations provided in the paper indicate certain flaws and simplifications resulting from the fact of the damping characteristic being assumed as the function of input velocity only, which is the case of simulation studies. An analysis of the results addressed in the paper highlights the impact of such factors as inertia of valves or cavitation on the profile of closed loop graphs of damping forces and point-type damping characteristics. It has been found that, on 


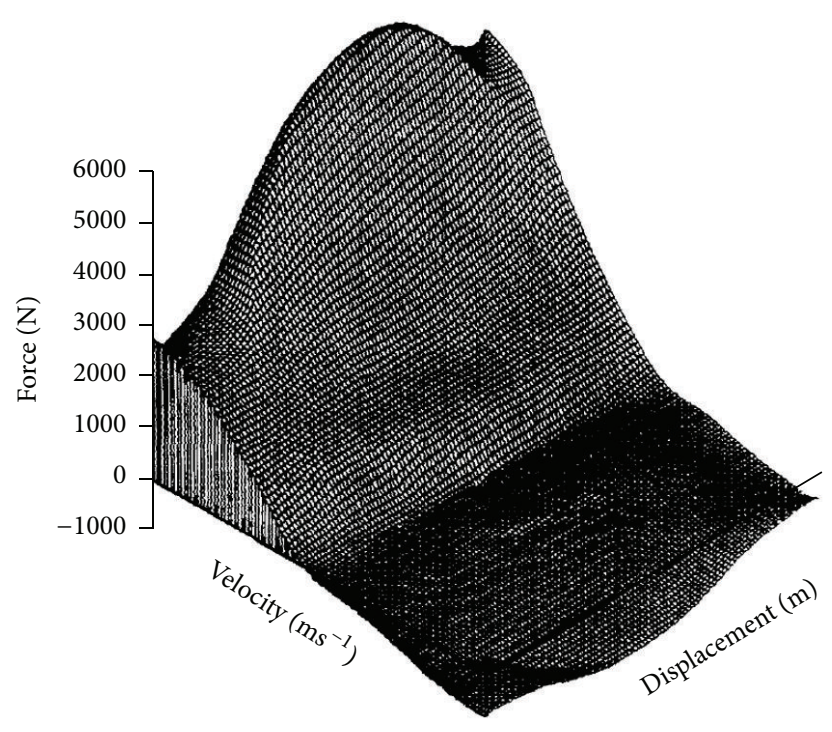

FIGURE 15: Area of damping forces in the function of input velocity and stroke [23].

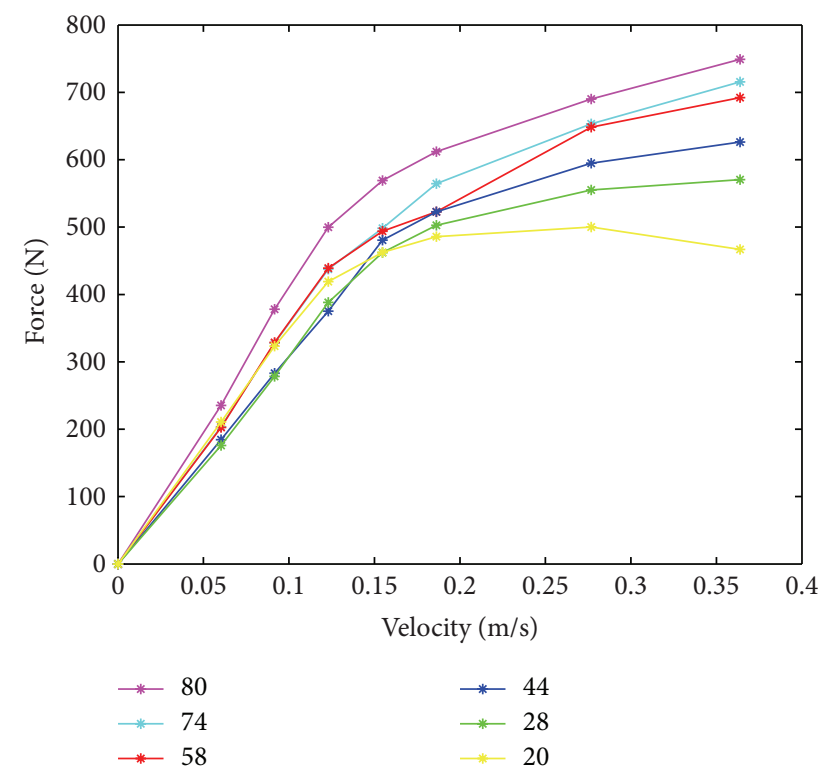

FIGURE 16: Velocity characteristics for the rebound motion (colours corresponding to individual stroke values).

higher velocities and short strokes, the point-type damping characteristics established display smaller forces in both the rebound and the compression motion. Consequently, in analyses which require more accurate representation of damping characteristics under different input function conditions, one should use the damping characteristic as a two-parameter area of $F=f(v, x)$.

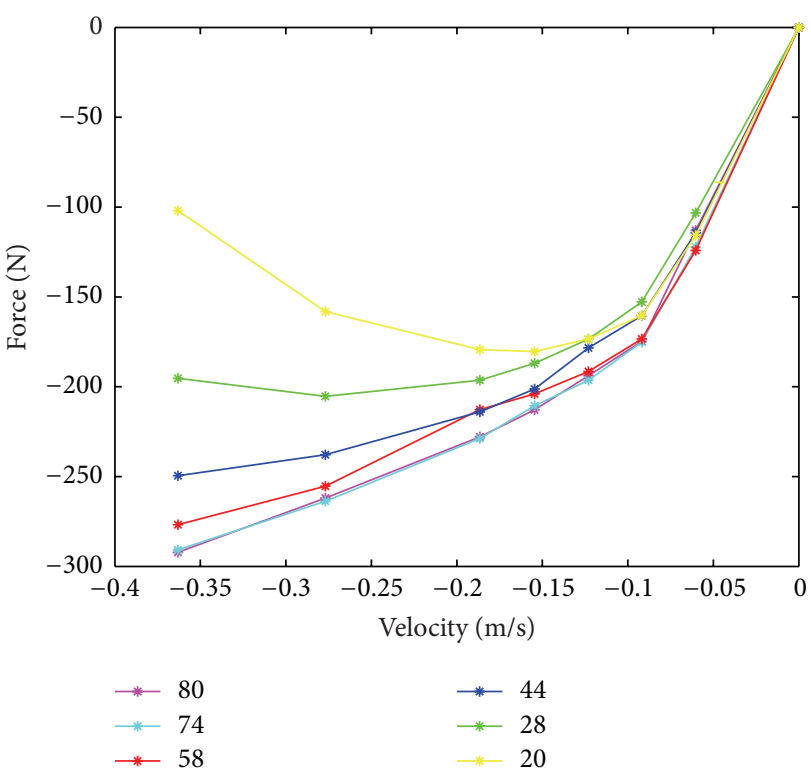

FIGURE 17: Velocity characteristics for the compression motion (colours corresponding to individual stroke values).

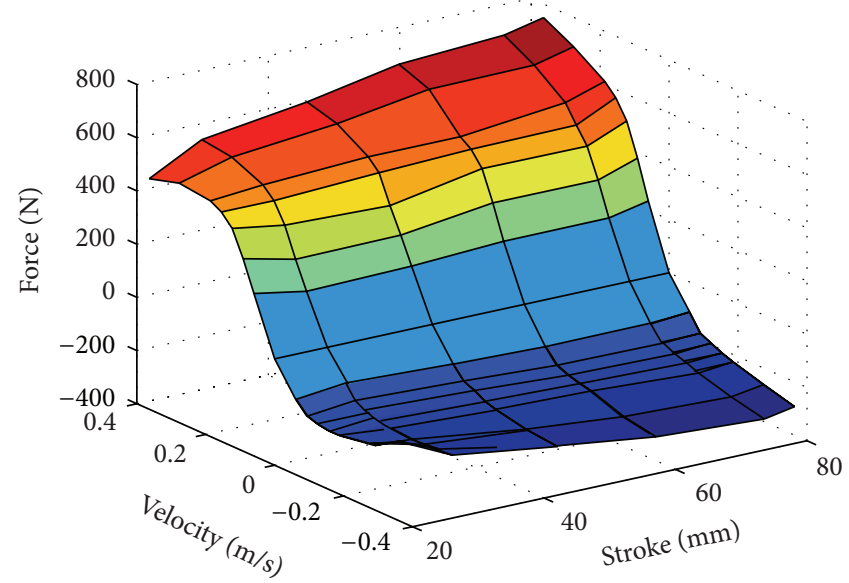

FIGURE 18: Area of damping forces in the function of velocity and stroke.

\section{Conflict of Interests}

The author declares that there is no conflict of interests regarding the publication of this paper.

\section{References}

[1] M. Kłaczyński and T. Wszołek, "Artificial intelligence and learning systems methods in supporting long-term acoustic climate monitoring," Acta Physica Polonica A, vol. 123, no. 6, pp. 1024-1028, 2013.

[2] M. Kłaczynśki and T. Wszołek, "Detection and classification of selected noise sources in long-term acoustic climate monitoring," Acta Physica Polonica A, vol. 121, no. 1, pp. A179-A182, 2012.

[3] M. Klaczynski, "Vibroacoustic methods in diagnosis of selected laryngeal diseases," Journal of Vibroengineering, vol. 17, no. 4, pp. 2089-2098, 2015. 
[4] A. Kruse, "Characterizing and reducing structural noises of vehicle shock absorber systems," SAE Technical Paper 2002-011234, 2002.

[5] A. Wieczorek, "Effects of construction changes in the teeth of a gear transmission on acoustic properties," International Journal of Occupational Safety and Ergonomics, vol. 18, no. 4, pp. 499507, 2012.

[6] Z. Dąbrowski and J. Pankiewicz, "Diagnosing a vehicle's suspension system on the basis of the non-linear effects of the dynamic response," Machine Dynamics Problems, vol. 26, no. 2-3, pp. 2741, 2002.

[7] D. Dąbrowski, W. Batko, W. Cioch, and H. Plascencia-Mora, "Model of the gears based on multibody system and its validation by application of non-contact methods," Acta Physica Polonica A, vol. 123, no. 6, pp. 1016-1019, 2013.

[8] D. Dabrowski and W. Cioch, "Analysis of signals pre-processing algorithm in case of hardware and software implementation on diagnostic programmable device PUD-2," Acta Physica Polonica A, vol. 123, no. 6, pp. 1020-1023, 2013.

[9] D. Laskowski, P. Łubkowski, E. Pawlak, and P. Stańczyk, "Anthropo-technical systems reliability," in Safety and Reliability: Methodology and Applications_-Proceedings of the European Safety and Reliability Conference, pp. 399-407, CRT Press, A Balkema Book, Taylor \& Francis Group, London, UK, 2015.

[10] B. Z. Lv, A. J. Hu, and S. H. Zhu, "Research on characteristics of damping force of hydro-pneumatic suspension," in History of Mechanical Technology and Mechanical Design, vol. 42 of Applied Mechanics and Materials, pp. 303-306, Trans Tech Publications, 2011.

[11] Ł. Konieczny and R. Burdzik, "Comparison of characteristics of the components used in mechanical and non-conventional automotive suspensions," Solid State Phenomena, vol. 210, pp. 26-31, 2014.

[12] http://www.mts.com/en/index.htm.

[13] R. Burdzik, "Research on the influence of engine rotational speed to the vibration penetration into the driver via feetmultidimensional analysis," Journal of Vibroengineering, vol. 15, no. 4, pp. 2114-2123, 2013.

[14] R. Burdzik, "Identification of structure and directional distribution of vibration transferred to car-body from road roughness," Journal of Vibroengineering, vol. 16, no. 1, pp. 324-333, 2014.

[15] R. Burdzik, "Implementation of multidimensional identification of signal characteristics in the analysis of vibration properties of an automotive vehicle's floor panel," Maintenance and Reliability, vol. 16, no. 3, pp. 458-464, 2014.

[16] J. Pankiewicz, P. Deuszkiewicz, J. Dziurdź, and M. Zawisza, "Modeling of powertrain system dynamic behavior with torsional vibration damper," Advanced Materials Research, vol. 1036, pp. 586-591, 2014.

[17] M. Zawisza, "Energy loss and the choice of damper of torsional vibration combustion engines," Solid State Phenomena, vol. 236, pp. 188-195, 2015.

[18] W. Bauer, Hydropneumatic Suspension Systems, Springer, Berlin, Germany, 2011.

[19] R. Burdzik and Ł. Konieczny, "Diagnosing of shock-absorbers of car vehicles at changeable pressure in tires," Diagnostyka, vol. 3, no. 51, pp. 27-32, 2009.

[20] M. Griffin, Handbook of Human Vibration, Academic Press, New York, NY, USA, 1990.

[21] R. N. Jazar, Vehicle Dynamics: Theory and Applications, Springer Science, Business Media, Berlin, Germany, 2008.
[22] J. Reimpel and J. Betzler, Passenger Car Chassis. Basic of Construction, WKiE, Warszawa, Poland, 2004.

[23] C. Surace, K. Worden, and G. R. Tomlinson, "An improved nonlinear model for an automotive shock absorber," Nonlinear Dynamics, vol. 3, no. 6, pp. 413-429, 1992.

[24] W. Matschinsky, Road Vehicle Suspension, John Wiley \& Sons, London, UK, 2000.

[25] M. Rau, Modellierung, simulation und auslegung eines hydropneumatischen federbeins mit schnell verstellbarer dämpfung [Diplomarbeit], Universität Stuttgart, Stuttgart, Germany, 2001.

[26] P. Yang, Y. H. Tan, J. M. Yang, and N. Sun, "Measurement, simulation on dynamic characteristics of a wire gauze-fluid damping shock absorber," Mechanical Systems and Signal Processing, vol. 20, no. 3, pp. 745-756, 2006.

[27] J. C. Dixon, The Shock Absorber Handbook, Society of Automotive Engineers, Warrendale, Pa, USA, 1999.

[28] T. D. Gillespie, Fundamentals of Vehicle Dynamics, SAE International, 1992.

[29] S. W. R. Duym, "Simulation tools, modelling and identification, for an automotive shock absorber in the context of vehicle dynamics," Vehicle System Dynamics, vol. 33, no. 4, pp. 261-285, 2000.

[30] S. Duym and K. Reybrouck, "Physical characterization of nonlinear shock absorber dynamics," European Journal of Mechanical and Environmental Engineering, vol. 43, no. 4, pp. 181-188, 1994.

[31] J. Warczek, R. Burdzik, and G. Perun, "The method for identification of damping coefficient of the trucks suspension," Key Engineering Materials, vol. 588, pp. 281-289, 2014.

[32] Y. Cui, T. R. Kurfess, and M. Messman, "Testing and modeling of nonlinear properties of shock absorbers for vehicle dynamics studies," in Proceedings of the World Congress on Engineering and Computer Science (WCECS '10), San Francisco, Calif, USA, October 2010.

[33] P. Czop, D. Sławik, P. Śliwa, and G. Wszołek, "Simplified and advanced models of a valve system used in shock absorbers," Journal of Achievements in Materials and Manufacturing Engineering, vol. 33, no. 2, pp. 173-180, 2009.

[34] P. Czop and D. Sławik, "A high-frequency first-principle model of a shock absorber and servo-hydraulic tester," Mechanical Systems and Signal Processing, vol. 25, no. 6, pp. 1937-1955, 2011.

[35] Y. Liu and J. Zhang, "Nonlinear dynamic responses of twintube hydraulic shock absorber," Mechanics Research Communications, vol. 29, no. 5, pp. 359-365, 2002.

[36] Ł. Konieczny, R. Burdzik, and J. Warczek, "The uncertainty of determining shock absorber damping characteristic on indicator test stand," Diagnostyka, vol. 14, no. 2, pp. 63-66, 2013.

[37] Ł. Konieczny, R. Burdzik, and B. Łazarz, "Application of the vibration test in the evaluation of the technical condition of shock absorbers built into the vehicle," Journal of Vibroengineering, vol. 15, no. 4, pp. 2042-2048, 2013.

[38] Ł. Konieczny, R. Burdzik, and J. Warczek, "Determinations of shock absorber damping characteristics taking stroke value into consideration account," Diagnostyka, no. 3, pp. 51-54, 2010. 


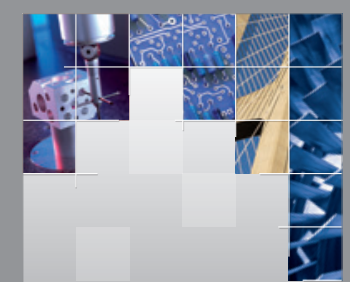

\section{Enfincering}
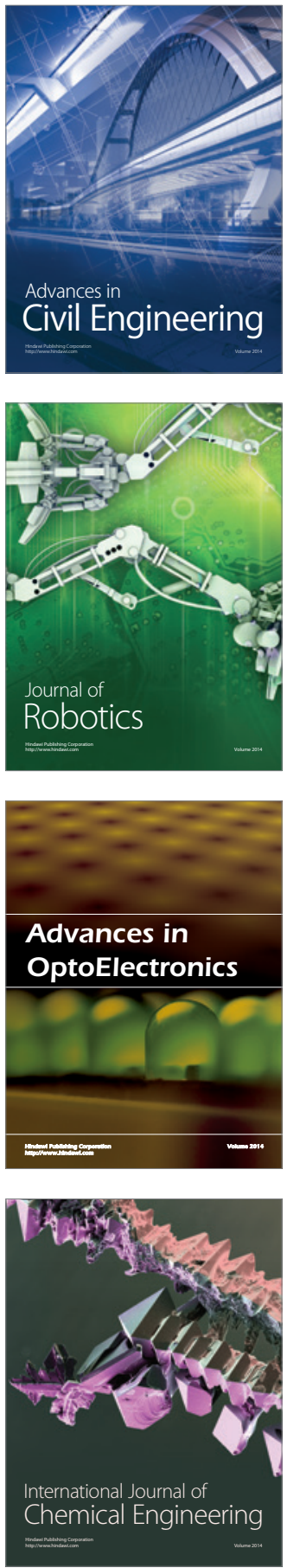

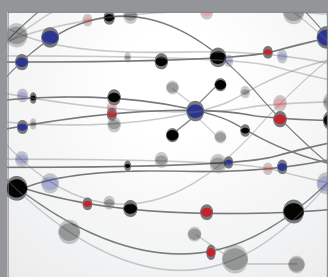

The Scientific World Journal

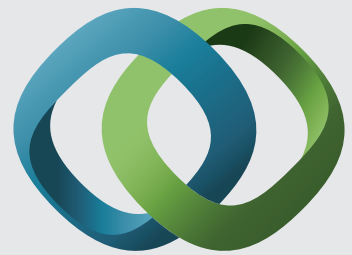

\section{Hindawi}

Submit your manuscripts at

http://www.hindawi.com
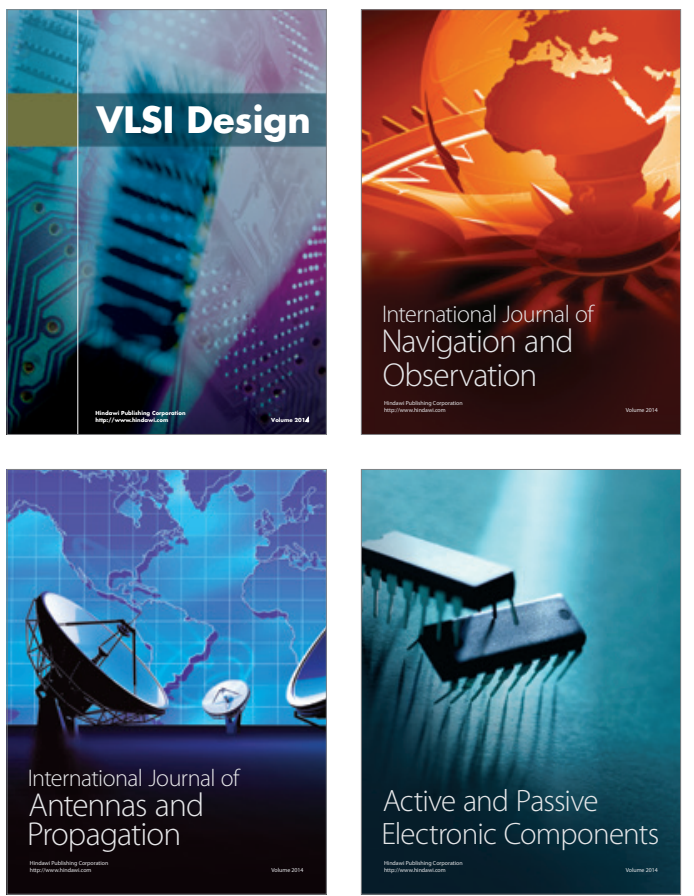
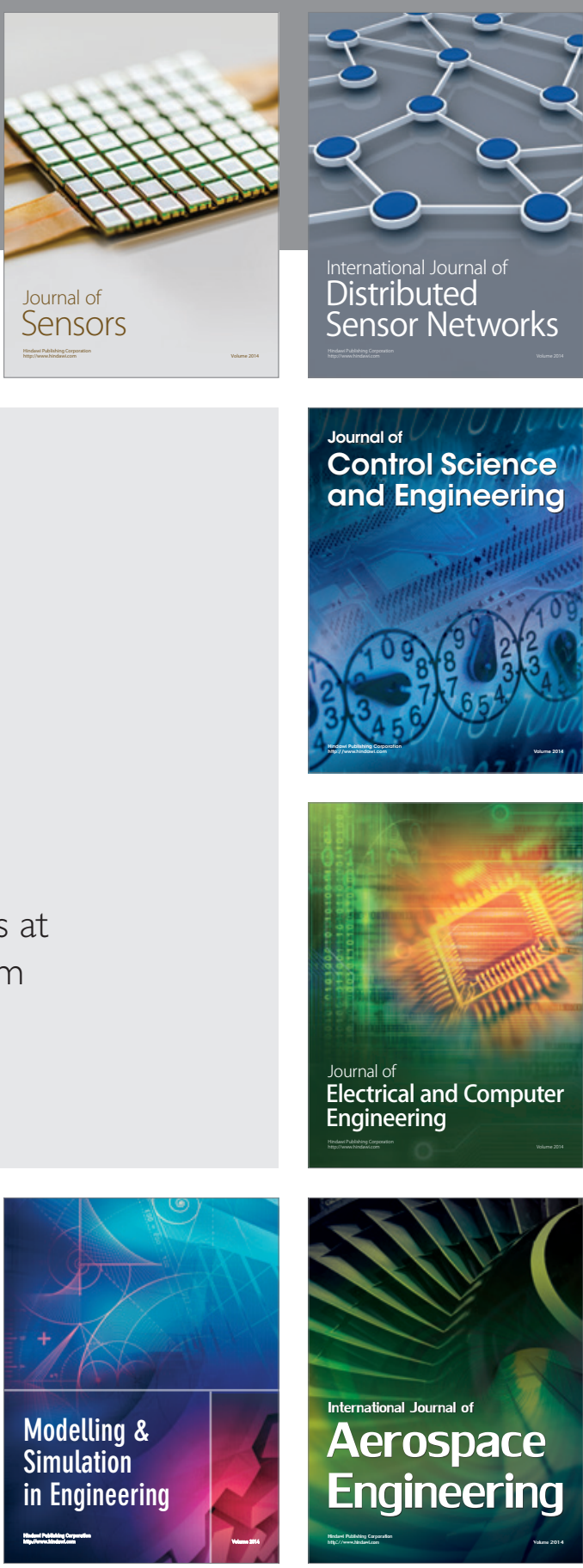

International Journal of

Distributed

Sensor Networks

Journal of

Control Science

and Engineering
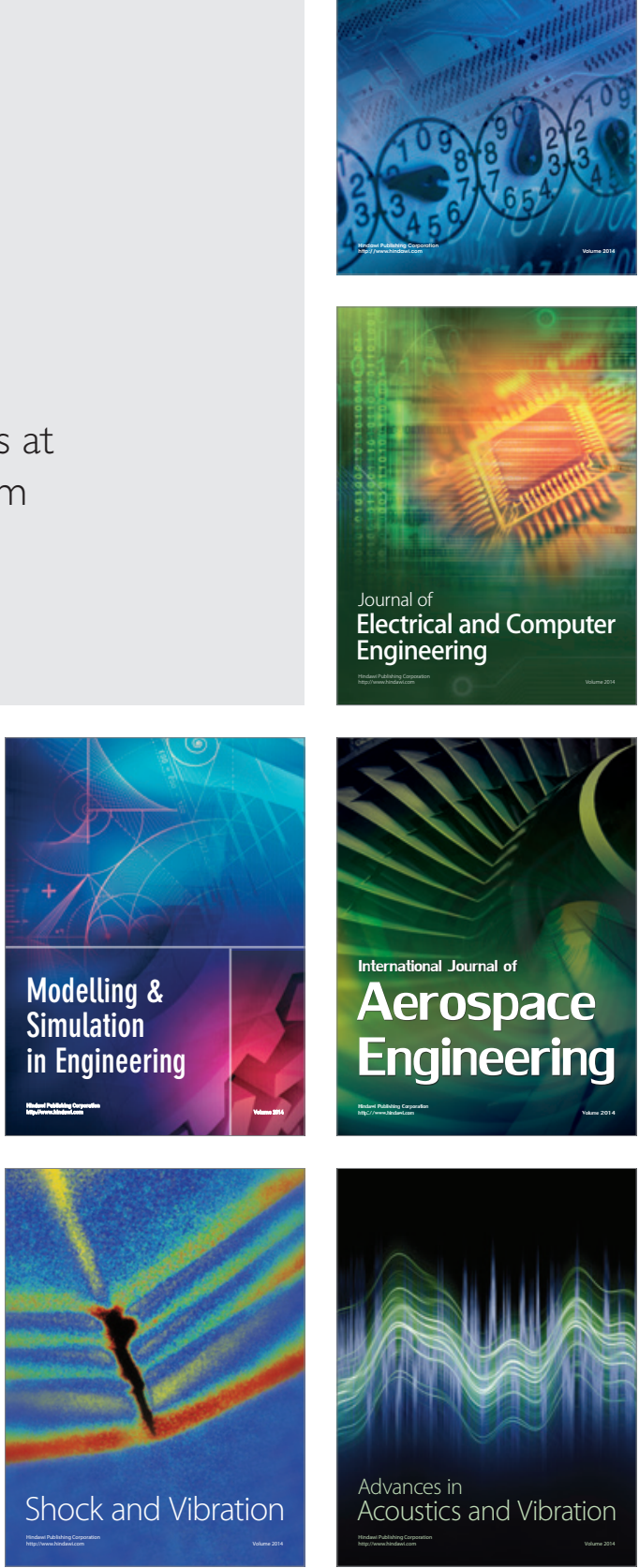